Sādhanā Vol. 40, Part 5, August 2015, pp. 1457-1472. (C) Indian Academy of Sciences

\title{
Optimization of PV array inclination in India using ANN estimator: Method comparison study
}

\author{
T V DIXIT*, ANAMIKA YADAV and S GUPTA \\ Department of Electrical Engineering, National Institute of Technology, \\ Raipur 0788-2202088, India \\ e-mail: tvdixit@gmail.com; ayadav.ele@nitrr.ac.in; sgupta.ele@nitrr.ac.in
}

MS received 28 October 2014; revised 16 January 2015; accepted 4 April 2015

\begin{abstract}
The network of solar power plants in distributed power system (in India) is growing exponentially. Since tilt angle affects the energy collection by solar panels, the conduction of experiments to find optimum tilt angle is expensive and time consuming in each location. Although different non-linear, empirical models have been proposed by different researchers in India, they have too many constraints and needs complex and rigorous computational effort each time. In this paper, a data driven approach such as ANN estimator has been proposed to estimate $\left(\beta_{\text {opt }}\right)$ at which solar energy collection of Photo-Voltaic Array (PVA) will be maximum at selected cities of India. The latitude $(\phi)$ elevation $\left(E_{\mathrm{L}}\right)$ from sea level and monthly mean hourly and daily global solar irradiance $\left(H_{\mathrm{g}}\right)$ of location are taken into account for this study. The ANN estimator takes $H_{\mathrm{g}}, \phi$ and $E_{\mathrm{L}}$ of site as inputs which are easily available and estimate optimum tilt angle almost instantaneously while testing. The proposed ANN estimator results are compared with analytical results. To validate the performance of ANN estimator results, statistical analysis study is carried out. Where, two statistical approaches such as descriptive method and Altman-Bland methods are applied. The ANA estimator results are found much close to ANA results at $95 \%$ confidence interval under statistical study.
\end{abstract}

Keywords. ANN; photovoltaic array; solar power; Altman-Bland method.

\section{Introduction}

India is one of the fastest growing countries in terms of energy consumption. At present this huge energy requirement of the country is met by the consumption of fossil fuels and other non-renewable sources. Where, solar energy is most valuable, clean, reliable and safe source of energy gifted by the nature. If it is used skillfully, it can reduce dependency on conventional energy sources and saves money as well as environment. The geographical location of India allows the country to receive well over $7000 \mathrm{MJ} / \mathrm{m}^{2}$ of solar energy each year, which is far

${ }^{*}$ For correspondence 
beyond the annual power consumption of India. Due to its location between the tropic of Cancer and the Equator, India has an average annual temperature that ranges from $25^{\circ} \mathrm{C}$ to $-27.5^{\circ} \mathrm{C}$. On the other hand being a tropical country, India has huge potential for solar power generation. Therefore, the solar plants will have an important share in the micro-grid in near future in India. The performance of solar plant is affected by the panel orientation and angle of tilt with the horizontal surface. In fact, big countries like India solar radiation measurement on a network scale is not possible in order to predict the performance of solar plant. In this connection several complex models are available in literature to estimate solar radiation in terms of climate parameters such as sunshine hour, relative humidity, cloud layer, and maximum temperature (Jamil \& Tiwari 2010; Gopinathan 1988; Garg \& Garg 1985; Modi \& Sukhatme 1979; Sukhatme \& Nayak 2008).

The performance of the solar plant can be maximized by adjusting orientation and tilt angle of PVA. Several methods have been proposed by researchers to derive the optimum angle of tile of PVA around the world from available metrological data on horizontal surface $\beta=0^{\circ}$ (Abhishek et al 2012; Murat et al 2004; Huseyin \& Arif 2007; Jamil \& Tiwari 2009; Armstrong \& Hurley 2010; Farzad \& Ali 2012; Hamid et al 2011; Emanuele 2013). In (Emanuele 2013) author has proposed an empirical formula to estimate optimum tilt angle $\left(\beta_{\text {opt }}\right)$, hour angle $(\omega)$ and orientation $(\gamma)$ of solar panel based on generic surface with respect to the position of sun. The ANN has been widely used in solar energy estimation problems to maximize the collection of total solar radiation $E_{\text {gsmax }}$ by panel (Ying \& Wang 2010; Abir \& Keyhani 2012; Kok et al 2012). The (Mubiru 2011) has proposed an ANN model to predict $H_{\mathrm{d}}$ daily beam radiation on horizontal surface while $H_{\mathrm{g}}$, maximum temperature, latitude, longitude and altitude of location are considered as inputs. Whereas, in (Abir \& Keyhani 2012) author has consider, $E_{\mathrm{g}}$ of each month, latitude $(\phi)$ of site as well as ground albedo $(\rho)$ as input but the effect of elevation $\left(E_{\mathrm{L}}\right)$ of location form sea level is ignored. The (Mubiru \& Banda 2007) have developed an ANNbased model to predict Ed based on six input such as sunshine hour, cloud cover, maximum temperature, latitude, longitude and altitude of location. The (Yaow et al 2005) presented the $\beta_{\text {opt }}$ calculation for fixed flat solar panel based on Genetic Algorithm (GA) and SimulatedAnnealing (SA) methods. The relation between sun incident angle and its radiation intensity on solar cell has been presented. The climate data of different location of Taiwan have been used by GA and SA to obtain the optimum tilt angle $\beta_{\text {opt }}$. A neural-genetic algorithm (Ying \& Wang 2010) has been proposed to determine the optimum tilt angle of photovoltaic module for Taiwan. In (Ying \& Wang 2010) Taguchi experiment is conducted at different tilt angle and seasons. This experimental data is fed ANN for training and ANN model predicts the output power of a specific tilt angle. At last GA was adopted to determine the $\beta_{\text {opt }}$ for PV module. In paper (Ahmet \& Ramazan 2012) author has applied ANN-based algorithm to acquire MPPT of PV system. In this paper limitation of data driven approach of ANN has been overcome by Genetic-Algorithm. In this case GA has been used to select the data from limited available data. The paper (Kok et al 2012) proposes an integrated ANN-PSO algorithm to track the solar power optimally under uncertain climate changes. In this paper, the ANN is used to predict the solar isolation level.

Till date no work has been reported to obtain $\beta_{\text {opt }}$ using soft computing in India. Therefore, the objective of this work is to determine optimum tilt angle $\left(\beta_{\text {opt }}\right)$ to maximize total monthly mean daily solar irradiance $H_{\mathrm{t}}$ for solar panel of the selected cities of India using ANN. Although the $\beta_{\text {opt }}$ problem can be formulated on daily, weekly, monthly, quarterly, bi-annual and annual basis. In this paper the quarterly, bi-annual and annual model of expected irradiance in $\left(\mathrm{MJ} / \mathrm{m}^{2}\right)$ is presented. The optimum tilt angle of south facing collectors of entire India is calculated on the basis of mean (monthly) global solar irradiance data obtained by Metrological center of 23 cities around the country (Ajit 2009). We have proposed an ANN estimator to predict the $\beta_{\text {opt }}$ (periodically), where mean monthly global solar irradiance of each month, latitude $(\phi)$ of site 
as well as effect of elevation $\left(E_{\mathrm{L}}\right)$ of location form sea level have been considered as input but ground albedo $(\rho)$ is not taken into account because the variation in $\rho$ is negligible and mostly it is assumed to be constant. A comparative study of the results obtained by Analytical Analysis (ANA) and ANN estimators is carried out. Further, the results analysis of ANN and ANA estimators are carried out based on statistical error tests. In this paper, the results of selected cities of India of different latitude and elevation such as Minicoy (MNC), Bangalore (BNG), Mumbai (MMB), Kolkata (KLK), Patna (PTN) and New Delhi (NDL) are presented due to space limitations.

\section{Mathematical model to find irradiance on inclined surface}

In general, sensors are placed in a horizontal position to measure direct solar irradiance at metrological centers. But in solar energy applications to maximize capture of total solar irradiance the panels are normally kept in tilted position. Hence, it becomes essential to derive total solar radiant exposure from available values of monthly mean of daily/hourly global solar irradiance and monthly mean of daily/hourly diffuse irradiance on the tilted panel surface. Sometimes, global solar irradiation data may either not be available or not be desired form. In such case a typical empirical regression (1) suggested by Gopinathan (Sukhatme \& Nayak 2008) can be considered when data on sunshine hours are available.

$$
\frac{H_{g}}{H_{o}}=a_{1}+b_{1}\left(\frac{S}{S_{\max }}\right),
$$

where $H_{\mathrm{g}}$ and $H_{\mathrm{d}}, S$ and $S_{\max }$ considered on horizontal surface $\left(\beta=0^{\circ}\right)$. The $a_{1}, b_{1}=$ $f\left\{\phi, E_{\mathrm{L}}, S, S_{\max }\right\}$ are regression constants can be obtained by (2-3) (Emanuele 2013; Sukhatme \& Nayak 2008).

$$
\begin{gathered}
a_{1}=-0.309+0.539 \cos \phi-0.0693 E_{L}+0.290\left(\frac{S}{S_{\max }}\right) \\
b_{1}=1.527+1.027 \cos \phi+0.0926 E_{L}-0.359\left(\frac{S}{S_{\max }}\right) .
\end{gathered}
$$

The extraterrestrial solar radiation on a horizontal panel for $d n$th day is given as (Farzad \& Ali 2012; Emanuele 2013; Abir \& Keyhani 2012)

$$
H_{O}=\frac{24}{\pi} G_{S c}\left(1+0.033 \cos \left(\frac{2 \pi \times d n}{365}\right)\right),
$$

where $G_{\mathrm{sc}}$ is the solar constant $\left(4.921 \mathrm{MJ} / \mathrm{m}^{2} / \mathrm{hr}\right)$. To simplify the calculation of $H_{\mathrm{o}}$, Klein has suggested that the extraterrestrial solar radiation in middle of the each month is nearly equal to the monthly mean value. The hour angle corresponding to sunrise or sunset on the horizontal surface is given in the following equation

$$
\bar{\omega}=\left[\cos ^{-1}(\tan \phi \tan \delta)\right] .
$$

Therefore, the corresponding sunshine hour is

$$
\bar{S}=\frac{2}{15}\left[\cos ^{-1}(\tan \phi \tan \delta)\right] .
$$


Equation (7) is suggested by Rabl to find the angle made by the line joining the centers of the sun and earth with the projection of this line on the equatorial plane, which known as declination angle $\delta$ (Ari 1975).

$$
\delta=\sin ^{-1}\left[-\sin (23.27) \times \cos \left(\frac{2 \pi D}{365.25}\right)\right],
$$

where $D$ - time after winter solstice, in days (i.e. $D$ count starts from 22 DEC onwards).

The downward solar radiant energy scatted by the suspended particle, air molecules and the clouds. Many researchers have developed empirical for estimating $H_{\mathrm{d}} / H_{\mathrm{g}}$ ratio for various part of world (Murat et al 2004; Farzad \& Ali 2012) and (Sukhatme \& Nayak 2008). In this case the prediction of mean monthly daily diffuse irradiance $\left(H_{\mathrm{d}}\right)$ on horizontal surface from $(8$ and 9$)$ is most suitable than other predictors because in fact diffuse components are much larger in India (Garg \& Garg 1985; Modi \& Sukhatme 1979).

$$
\begin{aligned}
& \frac{H_{d}}{H_{g}}=0.8677-0.7365\left(\frac{S}{S_{\max }}\right) \\
& \text { or } \frac{H_{d}}{H_{g}}=1.411-1.696\left(\frac{H_{g}}{H_{O}}\right) .
\end{aligned}
$$

\subsection{Solar irradiance on tilted surface}

The total solar irradiance $H_{\mathrm{t}}$ on tilted panel is the summation of direct-beam, diffuse and ground reflected radiations on the inclined surface. The $H_{\mathrm{t}}$ can be expressed as follows:

$$
H_{t}=H_{b} \Re_{b}+H_{d} \Re_{d}+H_{g} \Re_{r}
$$

where

- $H_{b}$ : daily beam radiation on horizontal surface is $H_{b}=\left(H_{g}-H_{d}\right)$

- $\Re_{b}$ : ratio of monthly mean beam irradiation on the tilted surface to the mean global solar irradiation for each month. The Liu and Jordan (Ajit 2009) have suggested that for sharp south facing $\gamma=0^{\circ}, \Re_{b}$ can be expressed as

$$
\Re_{b}=\frac{\omega_{s} \sin \delta \sin (\phi-\beta)+\cos \delta \cos \omega \cos (\phi-\beta)}{\omega_{s} \sin \delta \sin \phi+\cos \delta \cos \omega_{s} \cos \phi} .
$$

- $\Re_{d}$ : ratio of monthly mean daily diffuse radiation on tilted surface to that falling on horizontal surface.

$$
\Re d=(1+\beta) / 2 \text {. }
$$

- $\Re_{r}$ : ratio of reflected to incident radiation. The albedo or reflected solar radiant exposure from earth surface depends on nature of surface and on the angle of incidence of irradiance. If ground reflection to be considered as isotropic (Murat et al 2004) and (Jamil \& Tiwari 2009) then

$$
\Re d=\rho(1-\beta) / 2 .
$$

Generally, in India $\rho$ varies from 0.12 to 0.2 .

In Analytical method using Eqs. (1)-(13), several MATLAB programs are developed to estimate $\beta_{\text {opt }}$. For this $\beta$ has been searched in the search space $\left(0^{\circ} \leq \beta \leq 90^{\circ}\right)$ such that the total solar irradiance is maximum. 


\section{Optimum tilt angle forecasting of PVA using ANN}

In this section ANN-based prediction model has been proposed to predict $\beta_{\text {opt }}$ so that collection of total solar irradiance can be maximized by PVA. Further, the tedious and complicated analytical method has been replaced by ANN to estimate the nonlinear relation of tilt angle, latitude, elevation of site with the solar irradiance as shown in the following equation:

$$
\beta_{\text {opt }}=f\left\{H_{g_{(J a n-D e c)}}, \phi, E_{L}\right\} \text {. }
$$

In present study the MultiLayer Perceptron (MLP) structure has four layers: input layer, two hidden layers and output layer as shown in figure 1. The Levenbeg-Marquardt algorithm (a variation of Back propagation supervised learning algorithm) has been used for training due to its ability to tune weights for ANN in order to produce desired output to minimize Mean Square Error (MSE) during training and the associated error function is expressed in (15). The best performance of MLP structure depends on the selection of activation function and numbers of hidden layers and neurons in hidden layers.

$$
M S E=\frac{1}{N} \sum_{p} \sum_{k}\left(E_{p k}-O_{p k}\right)^{2},
$$

where $N$ is total number of training pattern or samples, $E_{\mathrm{pk}}$ is $k$ th element of target vector of $p$ th pattern and $O_{\mathrm{pk}}$ is $k$ th element of output vector of $p$ th pattern. In this paper a four layer network organized in 14 input nodes, 35 neurons in 1st hidden layer with 'LOGSIG' transfer function and 20 neurons in 2nd hidden layer with 'TANSIG'. In the output layer the number of nodes is equal to 4, 2, and 1 for Seasonal, Bi-annual and Yearly Tilt Angle prediction respectively. The available data from metrological centers are divided into training, validation or testing sets. The training data are uniformly sampled and normalized i.e. $\mathrm{P}_{\mathrm{j} \times 1} \in\{-1,1\}$ with $j \in\{1,2, \ldots, 14\}$ number of input.

The mathematical model of proposed ANN MLP structure with dimension of input, weight, bias of neuron and activation transfer function of each hidden layer is given by (16). Where, $P_{j \times 1} \in\left\{H_{g_{J a n}}, H_{g_{F e b}} \ldots H_{g_{D e c}}, \phi, E_{L}\right\}$ with $j \in\{1,2, \ldots 14\}$ number of the inputs at input layer of ANN.

$$
\beta_{i}^{o p t}=\left[W_{i \times 20}^{3} \cdot \tan \left\{W_{20 \times 35}^{2} \cdot \log \left(W_{35 \times j}^{1} \cdot P_{j \times 1}+b_{35 \times 1}^{1}\right)+b_{20 \times 1}^{2}\right\}+b_{i \times 1}^{3}\right],
$$

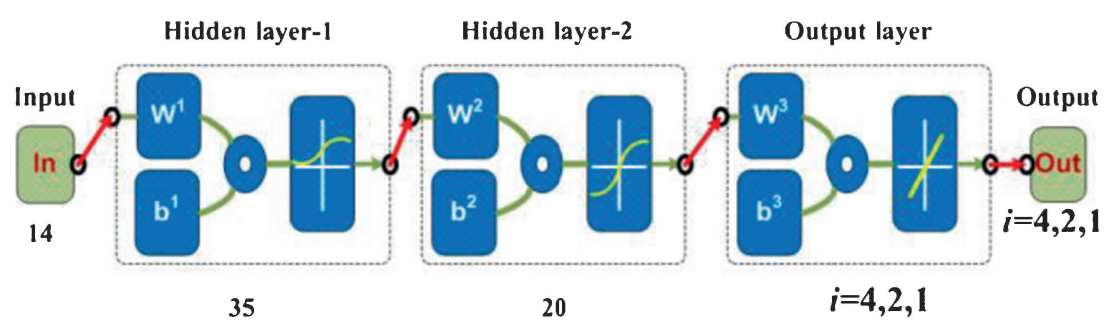

Figure 1. Inner layer and number of neurons in each layer of $\mathrm{ANN}$, where $i=4,2,1$ is the number of neurons in output layer for seasonal, bi-annual and yearly tilt angle respectively. 
where $i=4,2,1$ is the number of neurons in output layer for seasonal, bi-annual and yearly tilt angle respectively.

In training process known patterns pairs of input and output are fed to the NN and iteratively weights between the layers and bias are adjusted until the error between the desired output and the actual output from $\mathrm{NN}$ is below tolerance limit value of all the training sets.

\subsection{Training and test data}

The training patterns for ANN are obtained from Metrological and geographical data, these data are supplied by Indian Metrological Department, Pune (Ajit 2009). To train the ANN, hourly global solar radiation at different tilt angles are calculated with the help of tilt factors. The tilt factors at different tilt such as $\beta=0^{\circ}, \phi, \phi \pm 15^{\circ}, 22.5^{\circ}$ and $90^{\circ}$ are listed in (Ajit 2009). Hence, for each city 72 input (hourly global radiation for $12 \mathrm{~h}$ a day and at six different tilt angles) patterns of ANN are available. Therefore, total $1656(72 \times 23)$ input patterns of 23 cities are obtained from IMD, Pune for ANN estimator. Further, the 50\% of available patterns is fed for training and rest of the data to test the validity of ANN estimator. Moreover, the cities for which optimum tilt angles estimated during testing are not considered during training of the ANN.

To form target data $\left(\beta_{\text {opt }}\right)$ for training input patterns for ANN; experimental data such as hourly global solar radiation, hourly diffuse solar radiation, $\delta, E_{\mathrm{L}}$ and $\phi$ are taken from IMD, Pune (Ajit 2009). The different factors such as $\Re_{b}, \Re_{d}$ and $\Re_{r}$ are determined by Eq. (11)-(13) for all the range of $0^{\circ} \leq \beta \leq 90^{\circ}$. Using all above data total solar irradiance is determined using Eq. (10). Finally, $\beta_{\text {opt }}$ for different input patterns are selected at which $\mathrm{Ht}$ is maximum.

\subsection{Training results}

The training results of ANN estimator for seasonal optimum tilt angle are shown in figure 2. The training patterns are estimated for all four seasons such as winter (Nov, Dec, and Jan), autumn (Feb, Mar, and Apr), summer (May, Jun, and Jul) and spring (Aug, Sept, and Oct) period. The $\mathrm{NN}$ has been trained with the best training performance $7.5543 \mathrm{E}-07$ at 610 epochs. The training error results for all seasons are also plotted in figure 2. The absolute training error is found less than 0.043 degree.
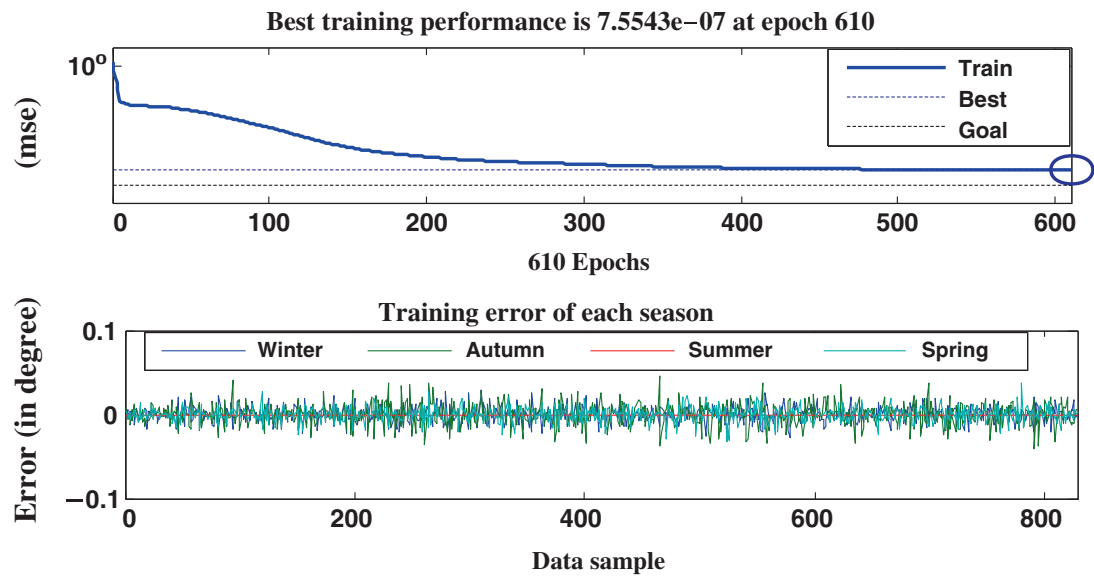

Figure 2. Training results of seasonal optimum tilt angle of selected cities of India using ANN. 

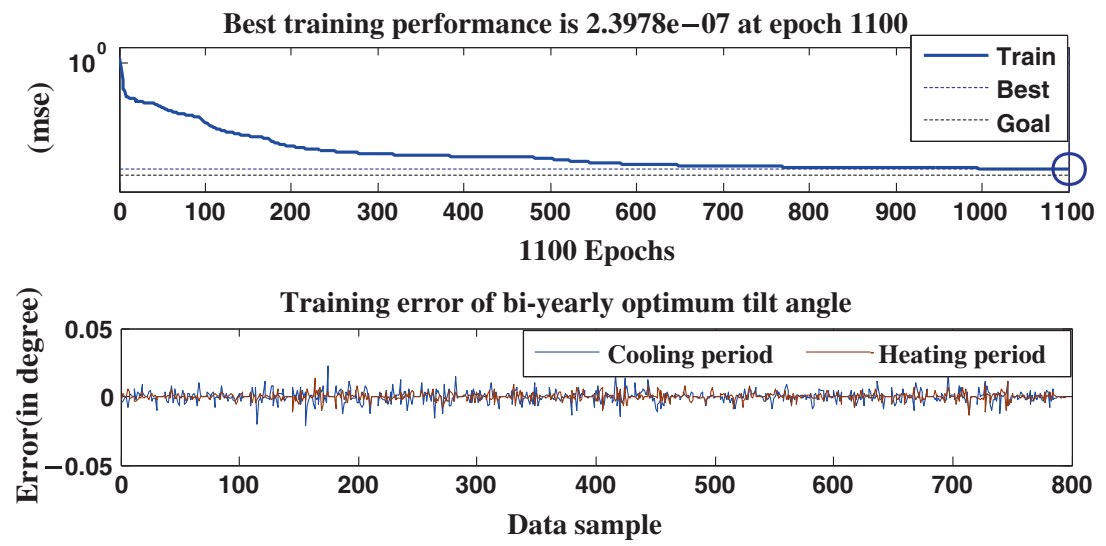

Figure 3. Training results of bi-annual optimum tilt angle of selected cities of India using ANN.
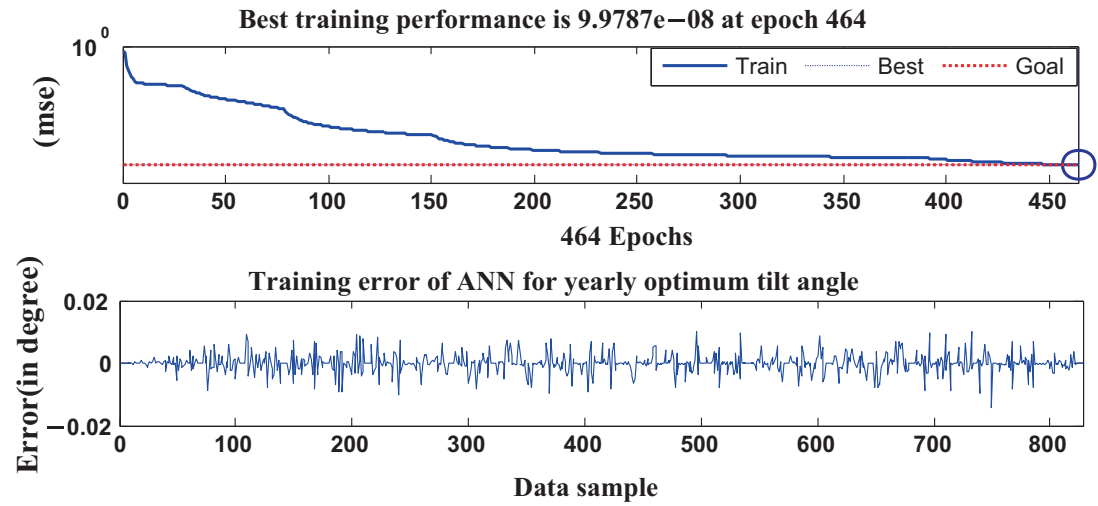

Figure 4. Training results of yearly optimum tilt angle of selected cities of India using ANN.

The bi-annual/bi-yearly MSE of training error is shown in figure 3. In this case tilt angle has been optimized for two times in a year one for HOT period (for the month of May to Oct) and the other is COL period (Nov to Apr). The target of ANN for this period is calculated based on GA for which data is obtained by rigorous calculation from the measured values at different tilt factors. In 1100 epochs, MSE of NN has reached to their best training performance of 2.3978E-07. During training absolute training error is 0.02 degree.

The MSE of training yearly $\beta_{\text {opt }}$ is shown in figure 4 , it reaches to its best training performance of $9.9787 \mathrm{E}-08$ at 464 epochs. Where, the absolute training error of yearly ANN estimator is found less than 0.01 . For this training 828 data samples of 23 cities are taken which are not considered for testing.

\section{Results and discussion}

In this paper the seasonal, bi-annual and annual optimum tile angles are predicted for selected cities of India using analytical method and ANN. These cities have distinct non-linear geographical and metrological features. In particular, the solar radiation data of India are considered by 
taking average on a monthly basis for period of 11 years (1991-2001) from Indian Meteorology Department (IMD) Pune, India. The exhaustive study of 23 cities has been carried out but due to space limitation the results of six selected cities of different latitudes are presented in this paper.

\subsection{Comparative study of analytical and ANN estimator}

Based on analysis presented in Section 2 several MATLAB program were developed to calculate the maximum total solar irradiance $\mathrm{Ht}_{\max }$ for $\gamma=0^{\circ}$ using (7-10). The optimum tilt angle of panel has been determined by searching for $\beta$ at which $\mathrm{Ht}$ is maximum. The inclination of PVA may be adjusted to optimum tilt angle hourly, daily and monthly basis. By shortening the adjustment period the total solar irradiance on PVA surface can be increased but these adjustments spend lot of manpower or electrical power in automatic tracking system. Therefore, in this paper seasonal, bi-annual/bi-yearly and yearly adjustment of tilt angle of flat surfaced PVA is considered for study.

4.1a Optimum tilt angle on seasonal basis: In this section simulation result for seasonal adjustment of tilt angle of expected total solar irradiance in $\left(\mathrm{MJ} / \mathrm{m}^{2}\right)$ is presented. The simulation result of ANN estimator for seasonal $\beta_{\text {opt }}$ shown in figure 5. In which percentage of data versus error for different class interval (in degree) has been plotted. From figure 5 it can be seen that number of samples whose error range in less than 2-3 degree are negligible and less than $6 \%$ of total testing data for all seasons. The simulation results of ANA and ANN estimator are presented in table 1 , represents $\beta_{\text {opt }}$ for each season and selected latitude. The total solar irradiance in $\left(\mathrm{MJ} / \mathrm{m}^{2}\right)$ for all three approaches to predict the optimum tilt angle is approximately the same as shown in table 2 .

4.1b Optimum tilt angle on bi-annual basis: The aim of this section is to predict the optimum tilt angle of PVA such that by adjusting it twice a year maximum solar irradiance $\mathrm{MJ} / \mathrm{m}^{2}$ can be achieved. Figure 6 shows the testing results of ANN for throughout heating and cooling period of the year. The percentage frequency of testing samples of ANN versus error class interval (in degree) is plotted in figure 6. The performance of ANN found better in cooling period than heating period of the year. Table 3 presents bi-annual optimum tilt angle of PVA for south direction $\left(\gamma=0^{\circ}\right)$. The bi-annual average of daily solar radiant exposure $\mathrm{Ht}_{\max }\left(\mathrm{MJ} / \mathrm{m}^{2}\right)$ for corresponding $\beta_{\text {opt }}$ for different cities is presented in table 4 .

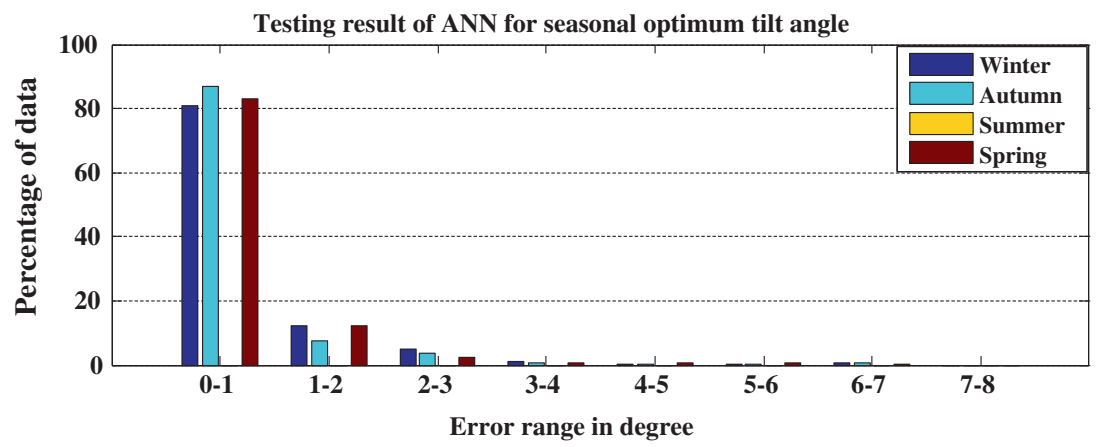

Figure 5. Testing results of seasonal optimum tilt angle of selected cities of India using ANN. 
Table 1. Optimum tilt angle of PVA (in degree) on seasonal basis using analytical method and ANN estimator.

\begin{tabular}{lrrrrrr}
\hline SNL opt & MNC & BNG & MMB & KLK & PTN & NDL \\
\hline WN $_{\text {ANA }}$ & 36.00 & 40.00 & 44.00 & 46.00 & 49.00 & 53.00 \\
AT $_{\text {ANA }}$ & 11.00 & 17.00 & 20.00 & 22.00 & 26.00 & 28.00 \\
SR $_{\text {ANA }}$ & 6.00 & 10.00 & 15.00 & 16.00 & 21.00 & 24.00 \\
WN $_{\text {ANN }}$ & 36.01 & 39.70 & 43.74 & 46.51 & 50.03 & 52.85 \\
$\mathrm{AT}_{\text {ANN }}$ & 11.14 & 16.77 & 20.00 & 22.40 & 26.44 & 27.86 \\
SR $_{\text {ANN }}$ & 6.72 & 9.87 & 15.19 & 16.53 & 21.54 & 24.01 \\
\hline
\end{tabular}

Note: During summer in all case optimum tilt angle is zero degrees.

4.1c Optimum tilt angle on annual basis: The ANN test results of annual optimum $\beta$ are shown in figure 7 in which percentage of data against range of error has been plotted. As it can be seen in figure 7, the $96 \%$ of testing sample of ANN has error less than 3-4 degree which is well within acceptance range. As shown in table 5 and table 6 the proposed ANN approach has better ability to locate the optimum solution than other methods.

\subsection{Statistical error analysis}

The statistical methods to assess agreement two quantitative methods such as ANA-ANN of prediction of optimum $\beta$ have been presented. Where, results obtained by ANN estimator have been compared with ANA results. Here, there are three statistical methods have been adopted such as descriptive analysis, direct comparison method and simple graphical (Altman \& Bland 1983) method. In direct comparison method it could be answered that whether one method of $\beta$ estimation might replace the other with sufficient accuracy. The merits of this approach are that the data will always cluster around a regression line and for comparing two methods it is much more informative. In graphical method difference versus mean of two methods is scattered and it is recommended that $95 \%$ of data points should lie within $( \pm 2 \mathrm{SD})$ of the mean difference. Where, Bland-Altman is a reliably simple graphical parametric approach based on analysis of variance. Here, numbers of MATLAB Program have been developed for statistical analysis.

Table 2. Maximum total solar irradiance $\mathrm{Ht}_{\max }\left(\mathrm{MJ} / \mathrm{m}^{2}\right)$ corresponding to optimum tilt angle of PVA on seasonal basis using analytical method and ANN estimator.

\begin{tabular}{lllllll}
\hline $\mathrm{Ht}_{\max }^{\text {SNL }}$ & MNC & BNG & MMB & KLK & PTN & NDL \\
\hline $\mathrm{WN}_{\text {ANA }}$ & 21.91 & 22.88 & 24.54 & 25.75 & 26.95 & 28.32 \\
$\mathrm{AT}_{\text {ANA }}$ & 19.57 & 19.85 & 20.39 & 20.80 & 21.22 & 21.70 \\
$\mathrm{SM}_{\text {ANA }}$ & 18.12 & 18.12 & 18.12 & 18.12 & 18.12 & 18.12 \\
$\mathrm{SR}_{\text {ANA }}$ & 16.96 & 17.13 & 17.48 & 17.77 & 18.06 & 18.40 \\
$\mathrm{WN}_{\text {ANN }}$ & 21.91 & 22.88 & 24.54 & 25.75 & 26.95 & 28.31 \\
$\mathrm{AT}_{\text {ANN }}$ & 19.57 & 19.85 & 20.38 & 20.80 & 21.22 & 21.69 \\
$\mathrm{SM}_{\text {ANN }}$ & 18.11 & 18.11 & 18.12 & 18.12 & 18.12 & 18.12 \\
$\mathrm{SR}_{\text {ANN }}$ & 16.96 & 17.13 & 17.47 & 17.76 & 18.06 & 18.39 \\
\hline
\end{tabular}

SNL means seasonal. 


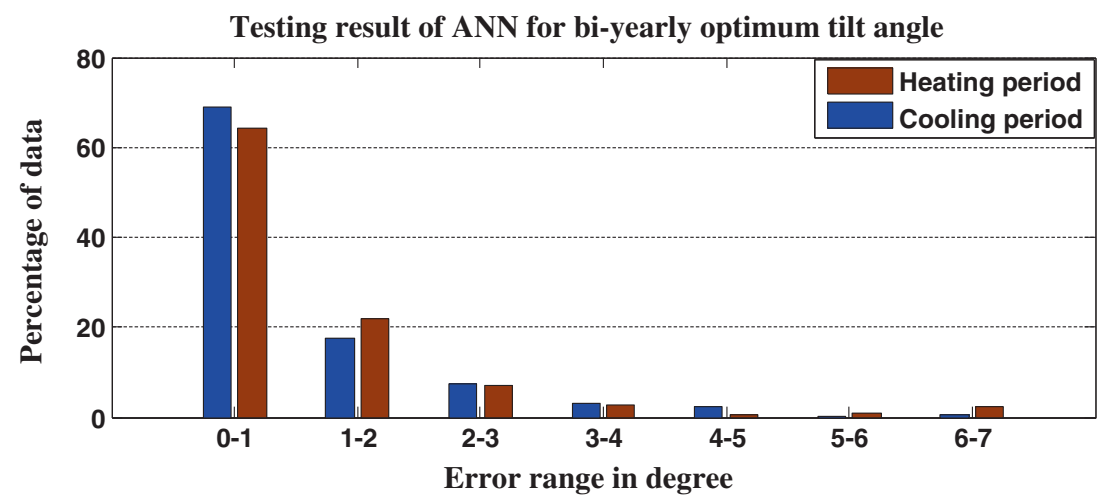

Figure 6. Testing results of bi-annual optimum tilt angle of selected cities of India using ANN.

4.2a Descriptive methods: The statistical test results of optimum tilt angle prediction of approaches under study (ANA and ANN) are presented in table 7 and table 8 for annual, biannual and seasonal period. Where, it can be observed that there is no significance difference in mean, standard deviation (SD) and median of all three methods (ANA and ANN) of $\beta_{\text {opt }}$ prediction of PVA but this estimation of agreement approach is less effective for larger estimation errors. The covariance and Pearson test result of correlation for two-sided t-test at $95 \%$ confidence interval for annual, bi-annual and seasonal period are given in tables 9 and 10 . The null hypothesis $\left(H_{0}: \rho=0\right)$ is rejected in favor of alternative hypothesis $\left(H_{0}: \rho \neq 0\right)$ at $5 \%$ significance level i.e. there is a significance correlation in ANA-ANN estimator result. In this section difference of mean, standard deviation (SD), median and correlation of multivariate analysis are explored to estimate the agreement of two methods. The correlation coefficient $(\rho)$ only measure the relation between methods but it does not guarantee the agreement between them. The change in scale of measurement/estimation does not affect the correlation unlike agreement. On the other hand some time data shows poor agreement but produces quite high correlation. Therefore, the correlation coefficient is of no use in practice to compare two methods for their agreement (Altman \& Bland 1983).

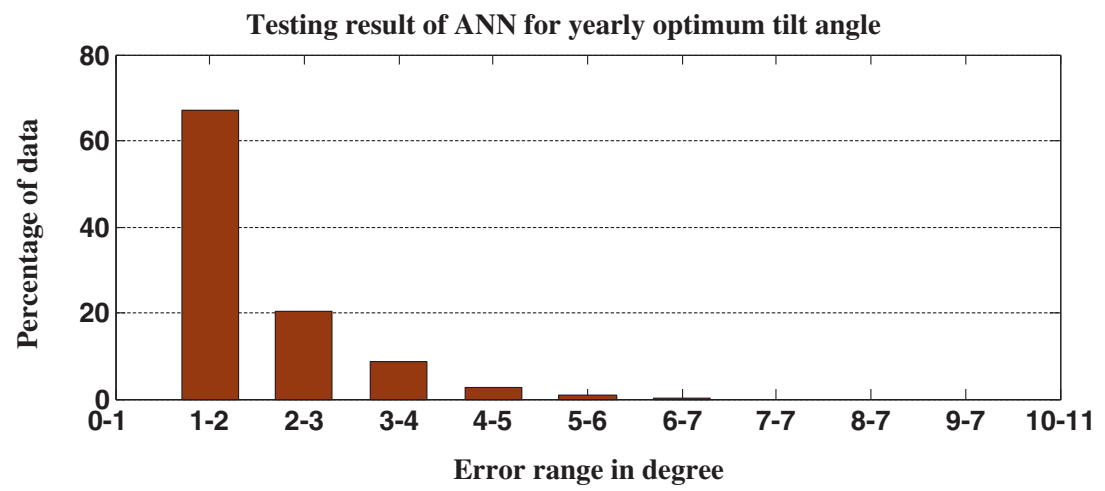

Figure 7. Testing results of yearly optimum tilt angle of selected cities of India using ANN. 
Table 3. Optimum tilt angle of PVA (in degree) on bi-annual basis using analytical method and ANN estimator.

\begin{tabular}{lrrrrrr}
\hline BYR & MNC & BNG & MMB & KLK & PTN & NDL \\
\hline COL $_{\text {ANA }}$ & 23.00 & 28.00 & 32.00 & 34.00 & 37.00 & 40.00 \\
HOT $_{\text {ANA }}$ & 0.00 & 0.00 & 2.00 & 4.00 & 8.00 & 10.00 \\
COL $_{\text {ANN }}$ & 23.27 & 27.38 & 32.00 & 34.88 & 37.03 & 40.41 \\
HOT $_{\text {ANN }}$ & 0.00 & -0.08 & 2.33 & 4.53 & 8.01 & 10.41 \\
\hline
\end{tabular}

BYR means Bi-annual period of tilt adjustment.

Table 4. Maximum total solar irradiance $\mathrm{Ht}_{\max }(\mathrm{MJ} / \mathrm{m} 2)$ corresponding to optimum tilt angle of PVA on bi-annual basis using analytical method and ANN estimator.

\begin{tabular}{lllllll}
\hline $\mathrm{Ht}_{\text {max }}$ & MNC & BNG & MMB & KLK & PTN & NDL \\
\hline COL $_{\text {ANA }}$ & 20.37 & 20.97 & 22.10 & 22.89 & 23.71 & 24.61 \\
HOT $_{\text {ANA }}$ & 17.49 & 17.50 & 17.47 & 17.55 & 17.63 & 17.75 \\
COL $_{\text {ANN }}$ & 20.37 & 20.98 & 22.10 & 22.89 & 23.70 & 24.61 \\
HOT $_{\text {ANN }}$ & 17.49 & 17.50 & 17.46 & 17.55 & 17.63 & 17.75 \\
\hline
\end{tabular}

Table 5. Optimum tilt angle of PVA (in degree) on yearly basis using analytical method and ANN estimator.

\begin{tabular}{lllllll}
\hline$\beta_{\text {opt }}$ & MNC & BNG & MMB & KLK & PTN & NDL \\
\hline ANA & 11.00 & 17.00 & 21.00 & 22.00 & 25.00 & 27.00 \\
ANN & 11.66 & 15.49 & 21.17 & 22.74 & 24.90 & 27.06
\end{tabular}

Table 6. Maximum total solar irradiance $\mathrm{Ht}_{\max }\left(\mathrm{MJ} / \mathrm{m}^{2}\right)$ corresponding to optimum tilt angle of PVA on bi-annual basis using analytical method and ANN estimator.

\begin{tabular}{lllllll}
\hline $\mathrm{Ht}_{\max }$ & MNC & BNG & MMB & KLK & PTN & NDL \\
\hline ANA & 18.42 & 18.60 & 19.18 & 19.65 & 20.09 & 20.61 \\
ANN & 18.42 & 18.62 & 19.20 & 19.65 & 20.09 & 20.61 \\
\hline
\end{tabular}

Table 7. Comparison of multivariate analysis result of annual $\beta_{\text {opt }}$ based on annual results.

\begin{tabular}{|c|c|c|c|c|c|c|}
\hline \multirow[t]{2}{*}{ Period/parameter } & \multicolumn{2}{|c|}{ Annual } & \multicolumn{2}{|c|}{ COL period } & \multicolumn{2}{|c|}{ Hot period } \\
\hline & $\overline{\mathrm{ANA}}$ & ANN & ANA & ANN & $\overline{\mathrm{ANA}}$ & ANN \\
\hline Mean & 22.0 & 21.9 & 33.9 & 34.1 & 4.8 & 4.7 \\
\hline SD & 5.40 & 5.58 & 5.50 & 5.66 & 4.3 & 4.1 \\
\hline Median & 24.0 & 23.8 & 35.0 & 35.4 & 5.0 & 4.7 \\
\hline
\end{tabular}

Table 8. Comparison of multivariate analysis result of seasonal $\beta_{\text {opt }}$.

\begin{tabular}{lrrrrrrr}
\hline Period/parameter & \multicolumn{2}{c}{ Winter } & & \multicolumn{2}{c}{ Autumn } & & \multicolumn{2}{c}{ Spring } \\
\cline { 2 - 4 } & ANA & ANN & & ANA & ANN & ANA & ANN \\
\hline Mean & 46.0 & 46.2 & 22.0 & 21.9 & 17.1 & 17.2 \\
SD & 5.7 & 5.7 & 5.2 & 5.2 & 6.5 & 6.3 \\
Median & 48.0 & 47.9 & 23.0 & 22.9 & 19.0 & 19.2 \\
\hline
\end{tabular}


Table 9. Comparison of multivariate analysis result of $\beta_{\text {opt }}$ based on annual results.

\begin{tabular}{lccc}
\hline Pair & Covariance & Correlation & 95\%CI \\
\hline ANA-ANN & 29.63 & 0.984 & $0.963-0.993$ \\
& \multicolumn{1}{c}{ Based on bi- annual results } & \\
COL $_{\text {(ANA-ANN) }}$ & 31.08 & 0.990 & $0.977-0.996$ \\
HOT $_{\text {(ANA-ANN) }}$ & 17.31 & 0.986 & $0.968-0.994$ \\
& Note: in all above cases $p<0.0001$. & \\
\hline
\end{tabular}

Table 10. Comparison of multivariate analysis result of seasonal $\beta_{\text {opt }}$.

\begin{tabular}{lcccc}
\hline Pair & Covariance & Correlation & $95 \%$ CI & $p$ \\
\hline WN $_{(\text {ANA-ANN })}$ & 31.07 & 0.997 & $0.994-0.999$ & $<0.0001$ \\
AT $_{\text {(ANA-ANN) }}$ & 26.80 & 0.999 & $0.998-1.000$ & $<0.0001$ \\
SR $_{\text {(ANA-ANN) }}$ & 41.22 & 0.996 & $0.990-0.998$ & $<0.0001$ \\
\hline
\end{tabular}

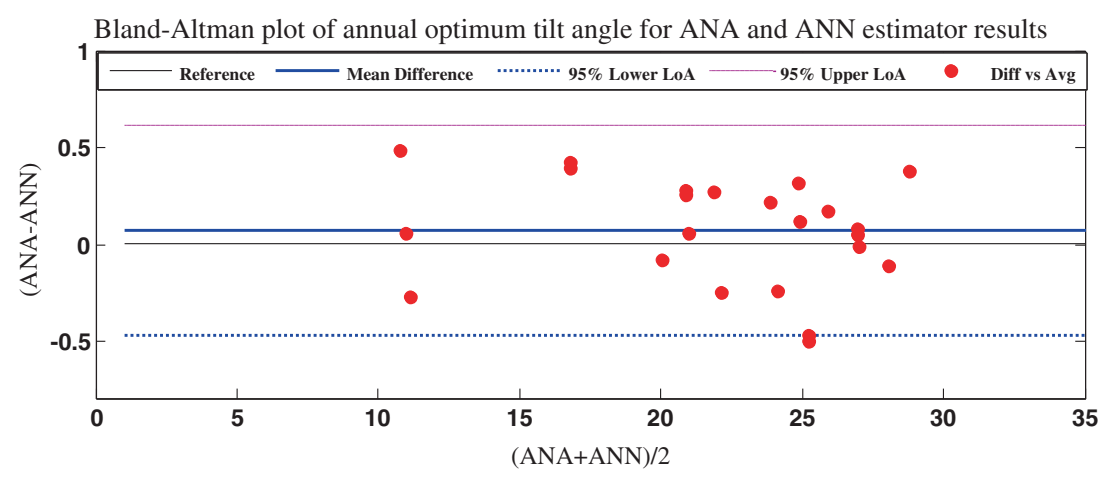

Figure 8. Bland-Altman plot of annual optimum tilt angle of ANA versus ANN estimator results.

4.2b Altman-Bland method: It is a most popular method followed by correlation coefficient and mean comparison. The (Altman \& Bland 1983) proposed a method for analysis of agreement by Bland-Altman plot and Limit of Agreement (LOA). In this approach the result of difference against average of two methods is plotted and the magnitude of disagreement (bias, error), spot outliers are evaluated to assess the trend. The Bland-Altman plot helps to investigate any possible relationship between the prediction error and the true value. Figure 8 shows comparison result of ANA versus ANN for annual optimum tilt angle. Here the MD of ANA versus ANN is 0.063 with $95 \%$ confidence interval $-0.375-0.692$.

Similar results for bi-annual $\beta_{\text {opt }}$ for all two approaches (ANA, ANN) under review are presented in figure 9. From figure 9, it can be concluded that in Cooling period one estimate out of 23 violated the LOA which is $4.35 \%$ of total predictions. This violation is due to some outlet data supplied by Srinagar metrological center. Moreover, in heating period the LOA are not violated. The MD for ANA versus ANN is under estimated by 0.032 degree and overestimated by 0.058 degree in cooling and heating period of the year respectively.

The Bland-Altman plots of seasonal results are shown in figure 10. In summer optimum tilt angle is zero degree in tropics because Sun is directly over the site/location. Therefore, in figure 10 for summer season all the data points are at reference (origin). Whereas, for other 

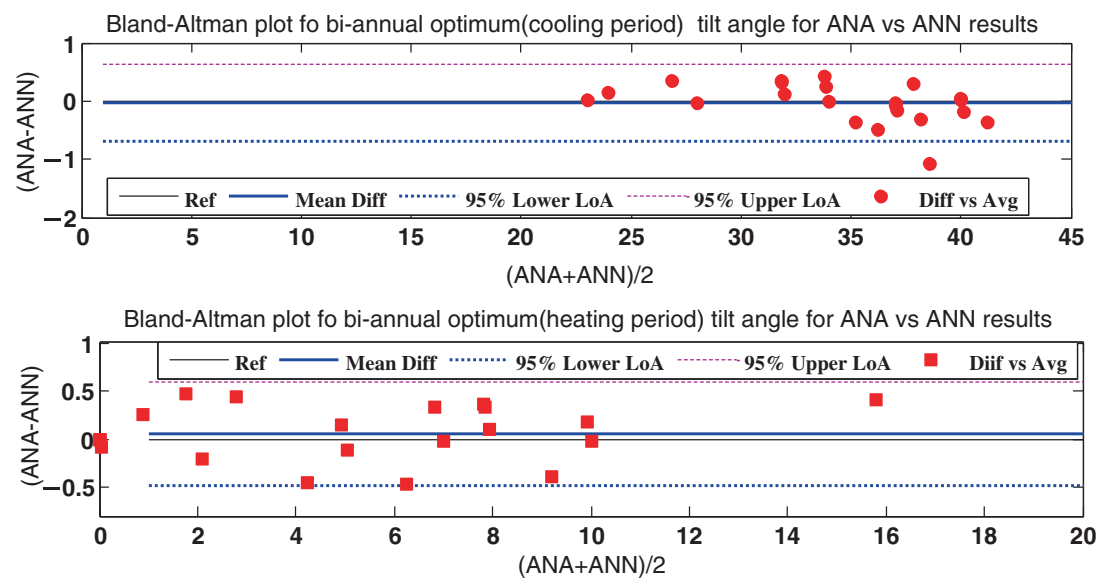

Figure 9. Bland-Altman plot of bi-annual optimum tilt angle of ANA versus ANN estimator results.
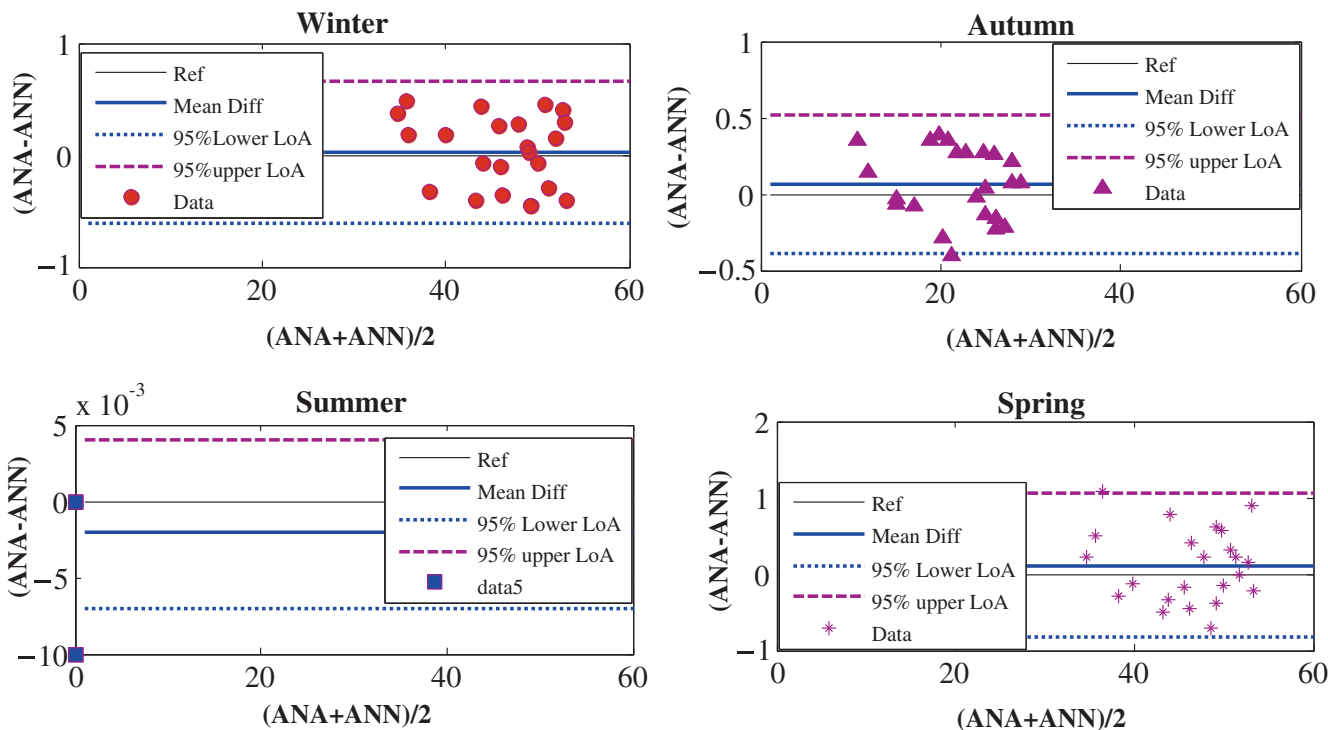

Figure 10. Bland-Altman plot of seasonal optimum tilt angle of ANA versus ANN estimator results.

seasons difference against average of results of two methods are scattered around mean difference but results are within LOA. The MD during winter, autumn, summer and spring are 0.86 , $0.041,-0.002$ and -0.065 respectively. Therefore, it can be concluded that there is no significant difference is ANN estimator results.

\section{Conclusion}

In this study, supervised learning approach has been used to train to ANN estimator which estimates the optimum tilt angle of solar panel to maximize the solar energy collection. However 
during testing, the ANN is used to find $\beta_{\text {opt }}$ for cities which have been not used in training. This proposed model is quick and easy to implement in real time once the ANN gets trained because it does not require rigorous iterative calculations unlike analytical method.

It is worthwhile to mention here that, out of 46 metrological stations in India, $91 \%$ stations have the facility of measuring $H_{\mathrm{g}}$ (using Thermoelectric Pyranometer). However, the facilities of measurement of diffuse irradiance and net radiation are available in 52\% and 13\% IMD stations respectively which are required by earlier reported schemes. On the other hand, the proposed ANN model can estimate the optimum tilt angle of any cities in India by just measuring $H_{\mathrm{g}}$, because $\phi$ and $E_{\mathrm{L}}$ of any site is fixed. Further, ANN model estimates of optimum tilt angle of 23 cities in India almost instantaneously while testing.

From this study is could be concluded that seasonal adjustment of tilt yield $5.56 \%$ extra energy collection than annual adjustment of tilt angle. Similarly, for bi-yearly adjustment energy collection is $2.91 \%$ more than yearly adjustment.

From the analysis it can also be concluded that ANN belongs to the class of data driven approach to forecast or predict the results. Nevertheless, if the target data are available for training ANN estimator gives better result for yearly and bi-annual optimum tilt angle. For estimation of seasonal optimum tilt angle, the ANN estimator is more effective, accurate and easy to implement. From statistical study it also can be concluded that because the ANN estimator results do not differ by some considered critical difference (at $95 \%$ difference of interval), the ANA calculation could be replaced by ANN estimator.

\section{Nomenclature}

$\begin{array}{ll}E_{\mathrm{L}} & \text { elevation of the site }(\mathrm{m}) \\ E_{\mathrm{g}} & \text { monthly mean hourly global solar irradiance }\left(\mathrm{MJ} / \mathrm{m}^{2} / \mathrm{h}\right) \\ H_{\mathrm{gmax}} & \text { maximum solar radiation collection by solar panel }\left(\mathrm{MJ} / \mathrm{m}^{2} / \text { day }\right) \\ H_{\mathrm{g}} & \text { monthly mean daily global solar irradiance }\left(\mathrm{MJ} / \mathrm{m}^{2} / \mathrm{day}\right) \\ H_{\mathrm{O}} & \text { monthly mean daily diffuse irradiance on horizontal surface }\left(\mathrm{MJ} / \mathrm{m}^{2} / \mathrm{day}\right) \\ S & \text { monthly mean Sun shine hour } \\ S_{\mathrm{max}} & \text { monthly mean maximum possible Sun shine hour per day at horizontal surface } \\ \text { Gsc } & \text { solar constant }\left(4.921 \mathrm{MJ} / \mathrm{m}^{2} / \mathrm{hr}\right) \\ \text { MSE } & \text { mean square error } \\ \text { PVA } & \text { photovoltaic array } \\ \text { ANA } & \text { analytical method } \\ \text { WN } & \text { winter } \\ \text { AT } & \text { autumn } \\ \text { SM } & \text { summer } \\ \text { SR } & \text { spring } \\ \text { HOT } & \text { heating period of the year } \\ \text { COL } & \text { cooling period of the year } \\ \text { SNL } & \text { seasonal tilt adjustment } \\ \text { SD } & \text { standard deviation } \\ \text { CI } & \text { confidence interval } \\ \text { LOA } & \text { limit of agreement } \\ & \end{array}$


Greek symbols

$\beta \quad$ slope or tilt angle of panel surface with respect to the horizontal surface (degree)

$\gamma \quad$ surface azimuth angle (degree)

$\delta \quad$ earth declination angle (degree)

$\rho \quad$ ground reflectance/ albado

$\phi \quad$ latitude of the site in (degree)

$\omega \quad$ hour angle (degree)

$\Re_{b} \quad$ tilt factor for beam radiation

$\Re_{d} \quad$ tilt factor for diffuse radiation

$\Re_{r} \quad$ radiation shape factor for surface w.r.t. surrounding ground

\section{References}

Abir Chatterjee and Ali Keyhani 2012 Neural network estimator of microgrid maximum solar power. IEEE Tran. Smart Grid 3(4): 1860-1866

Abhishek Agarwal, Vineet Kumar Vashishtha and Mishra S N 2012 Solar tilt measurement of array for building application and error analysis. Int. J. Renew. Energy Res. 2(4): 781-789

Ajit P Tyagi 2009 Solar radiant energy over India. MNRE Indian Metrological Department, New-Delhi

Armstrong and Hurley W G 2010 A new methodology to optimize solar energy extraction under cloudy condition. Renew. Energy 35: 780-787

Ahmet Afsin Kulaksiz and Ramazan Akkaya 2012 Training data optimization for ANNs using genetic algorithms to enhance MPPT efficiency of a stand-alone PV system. Turk. J. Elec. Eng. Comp. Sci. 20: 241-254

Altman D G and Bland J M 1983 Measurement in medicine: The analysis of method comparison studies. The Statistician Institute of Statisticians 32: 307-317

Ari Rabl 1975 Comparison of solar concentrators. Solar Energy 18: 93-111

Emanuele Calabr 2013 An algorithm to determine the optimum tilt angle of a solar panel from global horizontal solar radiation. J. Renew. Energy, Article ID 307547

FarzadJafarkazemi and Ali Saadabadi S 2012 Optimum tilt angle and orientation of solar surface in Abu Dhabi, UAE. Renew. Energy XXX: 1-6

Gopinathan K K 1988 A general formula for computing the coefficient of correlation connecting global solar radiation to sunshine duration. Solar Energy 41: 499

Garg H P and Garg S N 1985 Correlation of monthly-average daily global, diffuse and beam radiation with bright sunshine hours. Energy Conversion and Management 25: 409

Gunerhan Huseyin and Arif Hepbali 2007 Determination of the optimum tilt angle of solar collectors for building. Build. Environ. 42: 779-783

Hamid Moghadam, Farshad Farshchi Tabrizi and Ashkan Zolaghari Sharak 2011 Optimization of solar collector inclination. Desalination 265: 107-111

Jamil Ahemad M and Tiwari G N 2009 Optimization of tilt angle for solar collector to receive maximum radiation. Open Renew. Energy J. [Online], 2: 19-24

Jamil Ahemad M and Tiwari G N 2010 Solar radiation model - review. Int. J. Electr. Eng. 1(30): 513-532

James Mubiru 2011 Using artificial neural networks to predict direct solar irradiation. Hindawi J. Adv. Artif. Neural Syst. Vol. 2011, Article ID 142054, pp. 1-7, August

Kok B C, Goh H H and Chua H G 2012 Optimal power tracker for stand-alone photovoltaic system using Artificial Neural Network (ANN) and Particle Swarm Optimization (PSO). Proc. ICREPQ, Spain, 28-30 March

Modi Vijay and Sukhatme S P 1979 Estimation of daily total and diffuse isolationism India from weather data. Solar Energy 22: 407

Murat Kacira, Mehemt Smsek, Yunus Babur and Sedat Demirkol 2004 Determining optimum tilt angle and orientation of photovoltaic panel in sanliurfra, Yurkey. Renew. Energy 29: 1265-1275 
Mubiru J and Banda E J K B 2007 Estimation of monthly average daily global solar irradiation using artificial neural networks. Science-Direct J. Solar Energy 82: 181-187

Sukhatme S P and Nayak J K 2008 Solar energy principle of thermal collection and storage. Tata McGraw Hill, India

Yaow-Ming Chen, Chien-Hsing Lee and Hsu-Chin Wu 2005 Calculation of the optimum installation angle for fixed solar-cell panels based on the genetic algorithm and the simulated-annealing method. IEEE Trans. Energy Conversion 20(2): 467-473

Ying-Pin Chang and Der-An Wang 2010 Optimization of tilt angle for photovoltaic modules based on the neural-genetic algorithm. J. Nan Kai 7(1): 57-70 